\title{
Marilyn Li receives honorary lifetime membership
}

$\mathrm{D}$ r. Marilyn Li was awarded an honorary CAEP lifetime membership at the October 1999 CAEP/ AMUQ Scientific Assembly in Quebec City. Dr. Li has been active in pediatric emergency care in Canada for over 20 years. She was the first chair of the pediatric committee of CAEP before it became a formal section. She is a practising

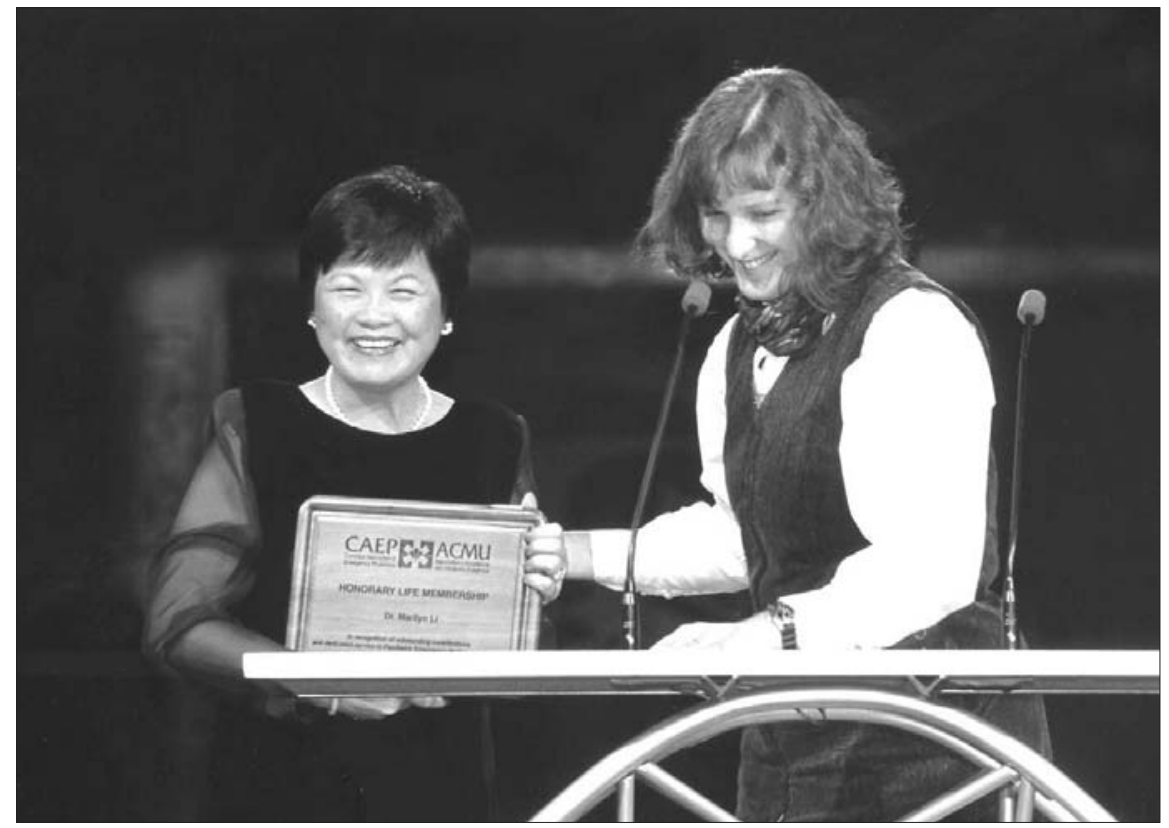

Dr. Cheri Nijssen-Jordan (R) presents Dr. Marilyn Li with CAEP's Honorary Life Membership pediatric emergency physician at the Children's Hospital of Eastern Ontario, where she was the department director until 1994.

Marilyn has been active in the promotion of pediatric emergency care at local, provincial, national and international levels. She recently completed her term as the Paediatric Representative to the Royal College Specialty Committee for Emergency Medicine, and is currently on the Royal College Accreditation Board. Dr. Li has been a leading light and a mentor for many of us in pediatric emergency medicine. Her teaching expertise and administrative skills are well known. CAEP is proud to honour this wonderful lady.

\section{Cheri Nijssen-Jordan, MD}

Division of Pediatric Emergency

Medicine

Alberta Children's Hospital and University of Calgary Calgary, Alta.

\section{Division of Emergency Medicine Earns Department Status}

Dalhousie's Board of Governors recently approved Emergency Medicine's change of status from a Division to a Department.

"This is only the second time in Canada that Emergency Medicine has been recognized as an academic department," says Dr. Doug Sinclair, Associate Professor and Head of the new Department of Emergency Medicine. "This will not change the academic and research activities Emergency Medicine has been involved in since its inception, but it better reflects what we do. It is certainly nice to have this distinction amongst our peers in the academic community."
Former Medical School Dean, Dr. Jock Murray established Emergency Medicine as a freestanding Division in 1992.

Dr. Sinclair credits former Deans Murray and Dr. John Ruedy for their vision and support for establishing Emergency Medicine as a specialty at Dalhousie, and says he looks forward to continued growth with the support of the school's new Dean, Dr. Noni MacDonald.

* Reprinted with permission from connection, a Dalhousie Medical School newsletter. 